\title{
Maternal mortality trends at the Princess Marina and Nyangabwe referral hospitals in Botswana
}

\author{
Ludo Nkhwalume ${ }^{1}$, Yohana Mashalla ${ }^{2}$
}

1. Ministry of Health, Institute of Health Sciences, Francistown, Botswana.

2. Faculty of Health Sciences, University of Botswana, Gaborone, Botswana.

\begin{abstract}
Despite the fact that about 94\% of pregnant women attend ANC, 95\% deliver at health facilities and 99\% deliveries are assisted by skilled birth attendants in Botswana, the national Maternal Mortality Rate is still high.

Objectives: To determine the trend of MMR at Princess Marina and Nyangabwe referral hospitals before and after EMOC training.

Methods: Retrospective longitudinal quantitative study design was used to collect data on maternal deaths. Demographic characteristics, maternal death causes, gestation at ANC registration and pregnancy risks were collected for the period before EMOC training and after training, analysed and compared. Descriptive statistics and frequency tables were used.

Findings: Maternal deaths were 33 and 41 before and after EMOC training respectively. Majority of the maternal deaths, $78.8 \%$ and $70.7 \%$ before and after EMOC training respectively occurred among young women in the reproductive ages. Eclampsia was the commonest cause of maternal death before EMOC between training \& and 58\% and $66 \%$ of maternal deaths before and after EMOC training respectively occurred among women who had attended ANC services four or more times.

Conclusion: Maternal deaths at the hospitals remained similar during the two periods. Qualitative studies are needed to determine why EMOC training has not resulted in significant reduction in MMR in Botswana.
\end{abstract}

Keywords: Maternal mortality trends, princess Marina, Nyangabwe referral hospitals, Botswana.

DOI: https://dx.doi.org/10.4314/ahs.v19i2.5

Cite as: Nkhwalume L, Mashalla Y. Maternal mortality trends at the Princess Marina and Nyangabwe referral hospitals in Botswana. Afri Health Sci.2019;19(2): 1833-1840. https:/ / dx.doi.org/10.4314/ahs.v19i2.5

\section{Introduction}

Under normal conditions pregnancy is a normal physiological process. However, the time of birth and shortly thereafter may pose life threatening to the mother and the child especially in the developing world ${ }^{1,2}$. To the mother, the worst outcome of pregnancy is maternal death. Maternal Mortality defined as maternal deaths per 100,000 live births is one of the measurable indicators of development within countries and for comparison between developing and developed countries ${ }^{3}$. Global effort to reduce maternal mortality rate (MMR) dates back to $1980 \mathrm{~s}$ when researchers highlighted the role of complications related to pregnancy and childbirth in death rates among

\section{Corresponding author: \\ Yohana Mashalla, \\ Faculty of Health Sciences, \\ University of Botswana, \\ Gaborone, Botswana. \\ Email: Yohana.mashalla@mopipi.ub.bw}

women of reproductive age and noted the inadequacy of attention paid to addressing largely preventable deaths ${ }^{4-6}$. The World Health Organisation (WHO) estimated about half a million women died annually from maternal caus$\mathrm{es}^{7}$. The Safe Motherhood Conference held in Nairobi in 1987 marked the beginning of a series of global initiatives calling for reducing MMR in developing countries by half in one decade. Strategies for achieving the goal included making family planning universally accessible, providing prenatal care and trained assistance at delivery and ensuring access to emergency obstetric care ${ }^{8}$. Between 1990 and 2015, an estimated 13.6 million women globally died from maternal causes and developing countries accounted for $99 \%$ of which sub-Saharan Africa contributed $66 \%$.

In September 2000, the United Nations (UN) General Assembly adopted the UN Millennium Declaration which was followed by an articulation of the Millennium Development Goals (MDGs). The MDG 5 called for a

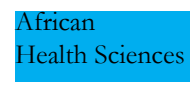

(C) 2019 Nkhwalume et al. Licensee African Health Sciences. This is an Open Access article distributed under the terms of the Creative commons Attribution License (https://creativecommons.org/licenses/BY/4.0), which permits unrestricted use, distribution, and reproduction in any medium, provided the original work is properly cited. 
$75 \%$ reduction between 1990 and 2015 in the $\mathrm{MMR}^{10}$. Building on the MDGs achievements, a new agenda for maternal health was proclaimed as part of the Strategic Development Goals ${ }^{11}$. In addition, the recent WHO Report "Strategies toward ending preventable maternal mortality (EPMM)" established supplementary national targets that no country should have MMR $>140$ per 100,000 live births and outlined a strategic framework to achieving these ambitious targets by $2030^{12}$.

Reports in Botswana indicate that $94 \%$ of women attend antenatal care services, 95\% deliver in health facilities while postnatal attendance is at $85.2 \% 0^{13}$. MMR in the country however, has indicated a fluctuating trend over the years. The 2007 Family Health Survey indicated that over $99 \%$ of the deliveries were assisted by skilled birth attendants in cities/towns, accounting for $97.2 \%$ in urban villages and $90.2 \%$ in rural areas. The report further indicated that over $95 \%$ of all reported deliveries occur in health facilities ${ }^{14}$. In 2005 the national MMR was 157; it increased to over 190 between 2008 and 2009 before declining to 163 in $2010^{15}$. MMR declined from 151.6 deaths/100,000 live births in 2014 to about 127 in 2015 before rising again to 156.6 in $2016^{14,16}$. These figures are still double the national MDG 5 target of reducing MMR to 81 by 2015 . Recent report suggests that $66 \%$ of maternal deaths occurred in the two major national referral hospitals in the country while $16 \%$ occurred in the district hospitals ${ }^{16}$. Timely availability of emergency transport services and prompt decision-making are necessary for improved perinatal outcomes ${ }^{7}$. In addition, promoting Emergency Obstetric Care (EMOC) and combining EMOC and skilled personnel have been reported to reduce maternal mortality in Western Europe and the US such that it is no longer a public health concern ${ }^{18}$.

In 2011, the Ministry of Health (MOH) in Botswana intensified Emergency Obstetric Care in-service training and structured maternal death audits as intervention strategies. The training program focused on critical areas including management of obstetric haemorrhage; abortion and anaemia; prolonged obstructed labour and premature labour; hypertensive disorders in pregnancy; puerperal infections and neonatal complications ${ }^{19}$. Since intensification of EMOC, the trend of maternal morality has not been studied. The purpose of this study was to assess the trend in the maternal mortality at the two na- tional referral hospitals in Botswana with a view to determine whether or not EMOC training influenced a change in reducing MMR at the studied facilities.

\section{Methods}

Study sites: The study was conducted in the two national referral hospitals; Princes Marina Hospital (PMH) in Gaborone and Nyangabwe Referral Hospital (NRH) located in the Southern and Northern part of Botswana respectively. The sites were selected because they admit patients for normal deliveries and those requiring specialised care referred from other lower level health facilities; high number of deliveries, live births, recorded higher maternal deaths than the lower level facilities and are mostly used for EMOC training.

Data collection: Quantitative approach was used to collect maternal mortality data in the study sites. Retrospective maternal mortality data was collected for the period between September 2010 and December 2011 (before EMOC training) and between September 2012 and December 2013 (post EMOC training). At NRH, maternal mortality data was generated from the deceased files while at PMH, a list of maternal deaths during the study periods was obtained and the Medical Records Unit provided the deceased files from which data was generated. Information on the age, marital status, gravida and parity, gestation age at registration for ANC and causes of maternal deaths were recorded.

Data handling: Data were anonymously coded and entered in the computer using excel spread sheet. The data were cleaned and double checked for entry errors. Descriptive statistics was used to characterise the findings and percentages were used to compare the number of deaths and causes of maternal deaths between the two periods.

Ethical considerations: The protocol received ethical clearance from the Ministry of Health Botswana (HPDME 13/18/1 VII 263), PMH (579), NRH (V 1.1) in Botswana and the University of Washington Ethics Committees (47276). The study used secondary data from the records departments and the findings of the study will be valuable resource to the institutions Audit Committees as guide for quality improvement. 
Findings: Social demographic characteristics and maternal deaths: Total of 35 audit reports of which 15 were from before EMOC training period $(2010$ - 2011) and 20 from after EMOC training period $(2012$ - 2013) were accessed. Maternal deaths increased from 33 before training to 41 after training. Most maternal deaths $(78.8 \%)$ and $(70.7 \%)$ occurred among women aged 20 through 35 before training and after training respectively. Maternal deaths were $84.9 \%$ and $70.7 \%$ among unmarried women before and after training respectively. Women who had become pregnant two to four times were $75.8 \%$ and $56.1 \%$ before and after training respectively and had the highest maternal deaths $45.5 \%$ and $51.2 \%$ respectively

Table 1: Social demographic characteristics of deceased women at PMH and NRH in the period 2010-2011 and 2012-2013

\begin{tabular}{|c|c|c|c|c|}
\hline \multirow{2}{*}{$\begin{array}{l}\text { Variables } \\
\text { Age (years) }\end{array}$} & \multicolumn{2}{|c|}{2010 - 2011} & \multicolumn{2}{|c|}{$2012-2013$} \\
\hline & $\mathrm{N}$ & $\%$ & $\mathrm{~N}$ & $\%$ \\
\hline $20-25$ & 13 & 39.4 & 9 & 22.0 \\
\hline $26-30$ & 7 & 21.2 & 7 & 17.1 \\
\hline $31-36$ & 6 & 18.2 & 13 & 31.7 \\
\hline $36-40$ & 6 & 18.2 & 9 & 22.0 \\
\hline $41-43$ & 1 & 3.0 & 3 & 7.3 \\
\hline Total & 33 & 100.0 & 41 & 100.0 \\
\hline \multicolumn{5}{|l|}{ Marital status } \\
\hline Single & 28 & 84.8 & 29 & 70.7 \\
\hline Married & 3 & 9.1 & 4 & 9.8 \\
\hline Living with partner & 1 & 3.0 & 2 & 4.9 \\
\hline Missing information & 1 & 3.0 & 6 & 14.6 \\
\hline Total & 33 & 100.0 & 41 & 100.0 \\
\hline \multicolumn{5}{|l|}{ Gravida } \\
\hline 1 & 2 & 6.1 & 8 & 19.5 \\
\hline 2 to 4 & 25 & 75.8 & 23 & 56.1 \\
\hline $5+$ & 5 & 15.2 & 7 & 17.1 \\
\hline Missinginformation & 1 & 3.0 & 3 & 7.3 \\
\hline Total & 33 & 100.0 & 41 & 100.0 \\
\hline \multicolumn{5}{|l|}{ Parity } \\
\hline P 0 & 1 & 3.0 & 1 & 2.4 \\
\hline $\mathrm{P} 1$ & 12 & 36.4 & 11 & 26.8 \\
\hline $\mathrm{P} 2-4$ & 15 & 45.5 & 21 & 51.2 \\
\hline P5+ & 4 & 12.1 & 5 & 12.2 \\
\hline Missing information & 1 & 3.0 & 3 & 7.3 \\
\hline Total & 33 & 100.0 & 41 & 100.0 \\
\hline
\end{tabular}


(Table 1).

Gestation at ANC registration and employment status

Table 2 presents gestation ages at onset of attendance to ANC and employment status. Before training, 42.4\% of the maternal deaths occurred among women who had not registered for ANC compared to $24.4 \%$ after training. About $54.6 \%$ and $63.4 \%$ of the maternal deaths occurred before and after training respectively among women who had registered for ANC during $2^{\text {nd }}$ and $3^{\text {rd }}$ trimester. Maternal deaths among the employed women were high 16 out of $18(88 . \%)$ before training and 14 out of $21(66.7 \%)$

Table 2: Gestation age at ANC registration and employment status among deceased women at PMH and NRH during the period 2010 - 2011 and 2012 - 2013

\begin{tabular}{lcccc}
\hline Gestation age at ANC registration & \multicolumn{2}{c}{$\mathbf{2 0 1 0} \mathbf{- 2 0 1 1}$} & \multicolumn{2}{c}{$\mathbf{2 0 1 2} \mathbf{- 2 0 1 3}$} \\
\hline & $\mathrm{N}$ & $\%$ & $\mathrm{~N}$ & $\%$ \\
Not registered & 14 & 42.4 & 10 & 24.4 \\
4 - 12 weeks & 1 & 3.0 & 2 & 4.9 \\
13 - 20 weeks & 9 & 27.3 & 19 & 46.3 \\
$21+$ weeks & 9 & 27.3 & 7 & 17.1 \\
Missing information & 0 & 0.0 & 3 & 7.3 \\
Total & 33 & 100.0 & 41 & 100.0 \\
Employment status & & & & \\
Unemployed & 18 & 54.5 & 21 & 51.2 \\
Employed & 9 & 27.3 & 13 & 31.7 \\
Missing information & 6 & 18.2 & 7 & 17.1 \\
Total & 33 & 100.0 & 41 & 100.0 \\
\hline
\end{tabular}

after training.

\section{Causes of maternal deaths}

Table 3 summarises the causes of maternal deaths. Sepsis and postpartum haemorrhage contributed 15 and 13 ma- ternal deaths respectively. Postpartum haemorrhage increased from $2(6.1 \%)$ before to $11(26.8 \%)$ after training. Deaths due to sepsis also increased also from 4 deaths before to 11 deaths after training. Other causes including those related to HIV did not seem to change during the

Table 3: Direct and indirect causes of maternal deaths among women recorded at the PMH and NRH between $2011-2011$ and 2012 - 2013

\begin{tabular}{lcccc}
\hline $\begin{array}{l}\text { Causes of maternal } \\
\text { deaths }\end{array}$ & $\mathbf{2 0 1 0} \mathbf{- 2 0 1 1}$ & \multicolumn{2}{c}{$\mathbf{2 0 1 2}$} & $\mathbf{- 2 0 1 3}$ \\
\hline & $\mathrm{N}$ & $\%$ & $\mathrm{~N}$ & $\%$ \\
Ruptured uterus & 0 & 0 & 1 & 2.4 \\
Postpartum haemorrhage & 2 & 6.1 & 11 & 26.8 \\
Abortion & 5 & 15.2 & 0 & 0.0 \\
Eclampsia & 8 & 24.2 & 4 & 9.8 \\
Sepsis & 4 & 12.1 & 11 & 26.8 \\
Antepartum haemorrhage & 0 & 0 & 3 & 7.3 \\
Postoperative & 1 & 3 & 1 & 2.4 \\
Anaemia & 6 & 18.2 & 3 & 7.3 \\
Others & 7 & 21.2 & 7 & 17.1 \\
Total & 33 & 100 & 41 & 100 \\
\hline
\end{tabular}


study periods.

Antenatal care attendance and risks associated with maternal deaths

Table 4 shows $12(36.4 \%)$ and 10 (24.4\%) of the maternal deaths occurred before and after training respectively among women who never attended antenatal care compared to $19(57.6 \%)$ before and $27(65.9 \%)$ after training among women who had registered and had made four or more ANC visits. For both periods, pregnancy induced hypertension was the most common risk followed by anaemia and previous caesarean section was common

Table 4: Antenatal care attendance and risks associated with maternal deaths among pregnant women recorded at PMRH and NRH during the period 2010 - 2011 and 2012 - 2013

\begin{tabular}{|c|c|c|c|c|}
\hline \multirow[t]{3}{*}{ Variables } & \multicolumn{4}{|c|}{ Maternal deaths } \\
\hline & \multicolumn{2}{|c|}{$2010-2011$} & \multicolumn{2}{|c|}{$2012-2013$} \\
\hline & $\mathrm{N}$ & $\%$ & $\mathrm{~N}$ & $\%$ \\
\hline \multicolumn{5}{|l|}{ Number of ANC visits } \\
\hline$<4$ & 1 & 3.0 & 2 & 4.9 \\
\hline 4 visits & 12 & 36.4 & 8 & 19.5 \\
\hline $5-10$ visits & 6 & 18.2 & 13 & 31.7 \\
\hline $11+$ visits & 1 & 3.0 & 6 & 14.6 \\
\hline Never attended & 12 & 36.4 & 10 & 24.4 \\
\hline Missing information & 1 & 3.0 & 2 & 4.9 \\
\hline Total & 33 & 100.0 & 41 & 100.0 \\
\hline \multicolumn{5}{|l|}{ Identified associated risks } \\
\hline Previous caesarean section & 1 & 3.0 & 4 & 9.8 \\
\hline Late ANC registration & 2 & 6.1 & 0 & 0.0 \\
\hline Pregnancy induced hypertension & 6 & 18.2 & 6 & 14.6 \\
\hline Low haemoglobin & 4 & 12.1 & 4 & 9.8 \\
\hline Spotting & 0 & 0.0 & 1 & 2.4 \\
\hline Elderly multiparity & 0 & 0.0 & 1 & 2.4 \\
\hline Grand multiparity & 0 & 0.0 & 1 & 2.4 \\
\hline Short stature & 0 & 0.0 & 1 & 2.4 \\
\hline Cardiac conditions & 0 & 0.0 & 1 & 2.4 \\
\hline Bronchial asthma & 0 & 0.0 & 1 & 2.4 \\
\hline Total & 13 & 39.4 & 20 & 48.8 \\
\hline
\end{tabular}

risk picked after training.

Complications detection during antenatal period One third (33.3\%) and $51.2 \%$ of all maternal deaths be- fore and after training respectively had complications detected at ANC visits. Pregnancy induced hypertension was more detected during antenatal visit after training than before training. HIV related complications account- 
Table 5: Complications of pregnancy at PMH and NRH identified at ANC visits during 2010 - 2011 and 2012 - 2013 periods

\begin{tabular}{lcccc}
\hline Variables & \multicolumn{3}{c}{ Identified complications at ANC } \\
\hline & \multicolumn{2}{c}{$2010-2011$} & \multicolumn{2}{c}{$2012-2013$} \\
& $\mathrm{~N}$ & $\%$ & $\mathrm{~N}$ & $\%$ \\
Pregnancy induced hypertension & 2 & 6.1 & 6 & 14.6 \\
Antepartum haemorrhage & 1 & 3.0 & 1 & 2.4 \\
Anaemia & 2 & 6.1 & 4 & 9.8 \\
HIV related complications & 6 & 18.2 & 6 & 14.6 \\
Premature rupture of membranes & 0 & 0.0 & 2 & 4.9 \\
Heart diseases & 0 & 0.0 & 1 & 2.4 \\
Perforate peptic ulcers & 0 & 0.0 & 1 & 2.4 \\
Total & 11 & 33.3 & 21 & 51.2 \\
\hline
\end{tabular}

ed for equal numbers in the two periods (Table 5).

\section{Discussion}

According to Statistics Botswana 2016, most MMR are related to direct cause, including genital tract and pelvic infections following abortion, followed by postpartum haemorrhage ${ }^{14}$. The major causes of maternal deaths in this study were postpartum haemorrhage, sepsis and abortion in that order. Among those who died from direct causes were also HIV infected supporting previous studies in the region ${ }^{20,21}$. Botswana has marked remarkable achievements in the fight against HIV and AIDS pandemic. Therefore, the deaths among HIV infected pregnant women is an interesting finding which could be due to undiagnosed and poorly understood co-morbidities by both care providers and the pregnant women. For both periods, the largest number of deaths occurred in the age group 20-30 years again supporting previous reports ${ }^{22}$.

We also found that maternal deaths were more common among unmarried than married women which ties well with the age range 20 - 30 years during which most women are still single. The high maternal deaths in this age range was not expected because young women have lower probability of giving birth at home compared to older women and are better users of skilled professional assistance therefore would have lower maternal deaths ${ }^{23-27}$. The deaths in this age group may be related to the frequency of abortion especially in countries where abortion is illegal except under certain conditions ${ }^{28,29}$.
There could also be other underlying factors related to the young pregnant women including delays in decision making, lack of awareness of risks related to pregnancy, inability to recognise signs and symptoms of impending complications that can explain the findings. In addition, factors related to practices and attitudes of care providers at health facilities e.g. delays in processing referrals, timely institution of appropriate intervention on admission and the quality of care provided during hospitalisation at the referral hospitals are likely to be influencing MMR in the country. These factors should be interrogated further to determine the contribution of each to the MMR.

Antenatal care services were introduced during the beginning of the $21^{\text {st }}$ century aimed to prevent and identify pregnancy risks in order to institute timely and appropriate management of pregnancy risks and treating the conditions $^{2,30}$. WHO recommends that a pregnant woman should have at least four ANC visits and the first should occur at or before the first 12 weeks of gestation. During ANC visits, the four components of ANC, including early detection of pregnant women at risk of any complications; action in order to prevent any future difficulties, diagnosis and treatment of pre-existing medical conditions and prompt referral should be instituted ${ }^{31}$. Previous reports have indicated that the proportion of women who attended four or more antenatal visits in the sub-Saharan Africa has actually fallen from 50\% in 1990 to $45 \%$ in 2010 due to low coverage, poor quality and inequities 
in the provision of ANC services ${ }^{32,33}$. The results in this study showed $57.6 \%$ and $65.9 \%$ maternal deaths occurred before and after training respectively among pregnant women who had registered and had made four and above ANC visits. Therefore, unlike in the developed countries, results in this study showed that attending antenatal care do not seem to translate to a reduction in maternal deaths and indicate that there could be other more complex factors influencing maternal deaths in these health facilities. Such factors could be related to the quality and adequacy of ANC services provided to the pregnant women.

It has been reported that the impact of antenatal screening on reduction of maternal mortality is limited to causes of maternal mortality with detectable preclinical phases $^{34}$. We found pregnancy induced hypertension; low haemoglobin and previous caesarean section were the most common risks in that order. These risks are known and have been recommended to constitute normal ANC packages that should be provided to pregnant women during ANC visit. Compared to the period before EMOC training, our results show an increase in detection of the risks in the post-training period. We however, because of the small number of recorded cases could not ascertain whether the trend was actually a result of EMOC training. This finding raised questions on the effectiveness of the EMOC training offered and its impact on provision of services in the health facilities. Because majority of the pregnant women had attended antenatal care consistently, we suggest that interventions for screening and management of preventable causes of maternal (direct and indirect) deaths at these facilities should be strengthened. In addition, investing on educating women on the importance of ANC; health care providers on the detection of risks related to pregnancy and instituting corrective measures timely are necessary for reducing MMR. Qualitative studies are needed to interrogate the effectiveness of the EMOC training programme among those who received the training. Focus should be on the course content, modes of delivery and assessment procedures as well as the knowledge and perceptions of the care providers on EMOC and ANC services.

\section{Limitations}

The findings in this study are based on a small number of health facilities in the country and small number of recorded maternal deaths at the health facilities. The cross-sectional nature of the study is another limitation that may influence the conclusions to be made. However, the study indicates that MMR is still high in Botswana, a high middle income country and calls for more comprehensive studies to explore options to reduce MMR in the country.

\section{Acknowledgement}

This study was supported by Afya Bora Consortium Career Development award funded by the University of Washington (Seattle) Centre for AIDS Research; subgrant award UWSC8082.

\section{Conflict of interest}

Authors declare no conflict of interest.

\section{References}

1. Murthy MSR, Murthy P V, Hari M, Kumar VKR, Rajasekhar K. Place of Birth: Why Urban Women Still Prefer Home Deliveries? J Hum Ecology. 2007; 21(2): 149-154. 2. Singh S, Remez L, Ram U, Moore AM, Audam, S. Barriers to Safe Motherhood in India. New York: Guttmacher Institute; 2009.

3. Walvaren G, Telfer M, Rowley J, Ronsmans C. Maternal mortality in rural Gambia: levels, causes and contributory factors. Bull World Health Organization. 2000; 78(5): 603 613.

4. Rosenfield A, Maine D. Maternal mortality - a neglected tragedy. Where is the M in MCH? Lancet. 1985; 326(8446): $83-85$.

5. Hogberg U. Maternal mortality - a worldwide problem. Int J Gynaecol \& Obstetrics. 1985; 23(6): 463 - 470.

6. Boerman T. The magnitude of the maternal mortality problem in sub-Saharan Africa. Soc Sci \& Med. 1987; 24(6): $551-558$.

7. World Health Organisation (1985). Maternal Mortality rates, unpublished report. WHO, 1985; Geneva.

8. Mahler H. The safe motherhood initiative: a call to action. Lancet. 1987; 329(8534): $668-670$.

9. WHO, UNICEF, UNFPA. Estimates TWB: Trends in maternal mortality; 1990 to 2010. Geneva, WHO; 2010. 10. United Nations (UN) Secretary General. Roadmap towards the implementation of the United Nations Millennium Declaration: Report of the Secretary General, New York 2001. No. A/56/326, p. 21. 
11. Transforming our world: the 2030 agenda for Sustainable development 2015. Resolution adopted by the General Assembly on 25 September 2015. UB General Assembly, Seventieth Session 2015; (A/RES/70/1. http://www.un.org/ga/search.view_doc.asp?symbol$=\mathrm{A} / \mathrm{RES} / 70 / 1$.

12. World Health Organisation. Strategies towards ending preventable maternal mortality (EPMM). Geneva. http:// www.everywomaneverychild.org/images/EPMM_final report_2015.pdf.

13. Botswana Family Health Survey. Central Statistics Office Botswana 2007.

14. Botswana Maternal Mortality Ratio 2016. Statistics Botswana (2018). http:/ / www.statsbots.org.bw.

15. Statistics Botswana. Botswana maternal mortality ratio (MMR) 2006-2010. www.cso.gov.bw

16. UN Partnership Botswana. Three years to go Botswana: Compact to Reduce Maternal Mortality. 2012.

17. Jammeh A, Sundby J, Vangen S. Barriers to Emergency Obstetric Care Services in Perinatal Deaths in Rural Gambia: A Qualitative In-Depth Interview Study. ISRN Obstetrics and Gynaecology. 2011; ArticleID981096, doi:10.5402/2011/981096.

18. Paxton A, Marine D, Freedman L, Fry D, Lobis S. The evidence for emergency obstetric care. Int J Gynaecol \& Obstetrics. 2005; 88(2): 181 - 193.

19. Ministry of Health Botswana. Guidelines for antenatal care and management of obstetric emergencies and prevention of mother to child transmission of HIV. 2010. 20. Abdool-Karim Q, Abouzahr C, Dehne K, Mangiaterra V, Moodley J, Rollins N, et al. HIV and maternal mortality: turning the tide. Lancet. 2010; 375 (9730): 19481949.

21. Yego F, D’Este C, Byles J, Williams JS, Nyongesa P. Risk factors for maternal mortality in a tertiary hospital in Kenya: a case control study. BMC Pregnancy and Childbirth. 2014; 14: 38.

22. Blanc AK, Winfrey W, Ross J. New Findings for Maternal Mortality Age Patterns: Aggregated Results for 38 Countries. Plos One. 2013; 8(4): e59864.doi: 10.1371/ journal.pone.0059864.

23. Ochako R, Fotso J, Ikamari L, Khasakhala A. Utilization of maternal health services among young women in Kenya: Insights from the Kenya Demographic and Health Survey, 2003. BMC Pregnancy and Childbirth. 2011; 11:1.

24. Baral YR, Lyons K, Skinner J, van Teijlingen ER. Ma- ternal health services utilisation in Nepal: Progress in the new millennium? Health Science Journal. 2012; 6 (4): 618633.

25. Mahapatro SR. Utilization of maternal and child Health care services in India: does Women's autonomy matter? The Journal of Family Welfare. 2012; 58(1): 22-33.

26. Saucedo M, Deneux-Tharaux C, Bouvier-Colle M. Ten years of confidential inquiries into maternal deaths in France, 1998-2007. Obstet \& Gynaecology. 2013; 122: $752-760$.

27. Kitui J, Lewis S, Davey G. Factors influencing place of delivery for women in Kenya: an analysis of the Kenya demographic and health survey, 2008/2009. BMC Pregnancy and Childbirth. 2013; 13: 40.doi: 101186/1471-239313-40.

28. United Nations. Abortion policy, Botswana. www. un.org/esa/population/publications/abortion/doc/botswal.doc, 2000.

29. Asamoah BO, Moussa KM, Stafstrom M, Musinguzi G. Distribution of Causes of Maternal Mortality among: different socio-demographic groups in Ghana; a descriptive study. BMC Public Health. 2011; 11: 159. Doi:10.1186/1471-2458-11-159.

30. World Health Organisation \& United Nations Children's Fund. Accountability for maternal, new born and child survival: The 2013 Update. Countdown to $2015 \mathrm{ma}$ ternal, new born and child survival. Geneva: WHO Press; 2013. From http://www.who.int/woman_acountability/ ierg/Countdown_Accountability_2013Report.pdf. Accessed October 2014.

31. Garrido GG. The impact of adequate prenatal care on Urban Birth Outcomes: An analysis in a developing country context. Economic development and cultural change. International Food Policy and Research Institute: University of Chicago; 2013.

32. United Nations. The Millennium Development Goals Report 2013. New York: United Nations; 2013. From http://www.un.org/millenniumgoals/pdf/report-2013/ mdg-report-2013-english.pdf. Accessed 25 October 2013. 33. Kinney MV, Kerber KJ, Black RE, Cohen B, Nkrumah F, Coovadia H, et al. Sub-Saharan Africa's Mothers, new-borns and children: Where and why do they die? PLoS Med. 2010; 7(6):e1000294.doi:10.1371/journal. pmed.1000294.

34. Oyinde K. Can Antenatal Care Result in Significant Maternal Mortality Reduction in Developing Countries? Community Med Health Education. 2013; 3: e116. Doi:104172/2161-0711.1000e116. 